\title{
Profiles of Helicopter Parenting, Parental Warmth, and Psychological Control During Emerging Adulthood
}

\author{
Laura M. Padilla-Walker \\ Brigham Young University, laura_walker@byu.edu \\ Daye Son
}

Larry J. Nelson

Follow this and additional works at: https://scholarsarchive.byu.edu/facpub

Part of the Social and Behavioral Sciences Commons

\section{Original Publication Citation}

Padilla-Walker, L. M., *Son, D., \& Nelson, L. J. (2019, onlinefirst). Profiles of helicopter parenting, parental warmth, and psychological control during emerging adulthood. Emerging Adulthood

\section{BYU ScholarsArchive Citation}

Padilla-Walker, Laura M.; Son, Daye; and Nelson, Larry J., "Profiles of Helicopter Parenting, Parental Warmth, and Psychological Control During Emerging Adulthood" (2019). Faculty Publications. 5501. https://scholarsarchive.byu.edu/facpub/5501 accepted for inclusion in Faculty Publications by an authorized administrator of BYU ScholarsArchive. For more information, please contact ellen_amatangelo@byu.edu. 


\title{
Profiles of Helicopter Parenting, Parental Warmth, and Psychological Control During Emerging Adulthood
}

Emerging Adulthood

202।, Vol. 9(2) 132-I44

(C) 2019 Society for the

Study of Emerging Adulthood

and SAGE Publishing

Article reuse guidelines:

sagepub.com/journals-permissions DOI: I0.1 I77/21676968|8823626 journals.sagepub.com/home/eax

@SAGE

\author{
Laura M. Padilla-Walker', Daye Son', and Larry J. Nelson'
}

\begin{abstract}
The current study used a person-centered approach to investigate different profiles of helicopter parenting in conjunction with parental psychological control and parental warmth. Child outcomes of parenting profiles were also examined. Participants consisted of 458 emerging adults who completed questionnaires at age 19 (5I\% female, $33 \%$ from single families, $74 \%$ college students). Latent profile analyses were conducted separately for mothers and fathers, and profiles included "warm helicopter" parents (77\% of mothers, $50 \%$ of fathers), "controlling helicopter" parents (20\% of mothers, $12 \%$ of fathers), "low-involved" parents (3\% of both mothers and fathers), "average" fathers (30\%), and "high controlling helicopter" fathers (4\%). Parenting profiles were differentially associated with children's school engagement, depression, and delinquency. Discussion focused on the relatively low salience of helicopter parenting in relation to other aspects of parenting and the implications for emerging adult children's development.
\end{abstract}

\section{Keywords}

helicopter parenting, profile analysis, emerging adulthood, parenting

Emerging adulthood is a developmental period characterized by instability, uncertainty, and exploration in various aspects of life such as identity and education (Arnett, 2000). As emerging adults experience role fluctuations, their relationships with parents also undergo changes. The process of reshaping parent-child relationships during emerging adulthood is of particular importance as parents continue to influence emerging adults' development (Nelson \& Padilla-Walker, 2013) and since successful individuation separation from parents is critical to identity development and well-being of emerging adults (Koepke \& Denissen, 2012). Ideally, the previous hierarchical parent-child relationship would transform into a more symmetrical relationship between two autonomous adults (Aquilino, 1997) while maintaining ongoing connectedness with and support from parents (Hair, Moore, Garrett, Ling, \& Cleveland, 2008). Indeed, healthy parent-child relationships in emerging adulthood encompass a balance between connection (Fingerman \& Yahirun, 2015) and autonomy (Smollar \& Youniss, 1989). Achieving this developmentally appropriate parentchild relationship may be challenging for some families as many emerging adult children (Arnett \& Schwab, 2012) and their parents (Nelson et al., 2007) tend to perceive emerging adults as not yet being fully adults but report that parents have legitimate authority over their child's lives (Padilla-Walker,
Nelson, \& Knapp, 2014). Parents who hold this view may be prone to pose threats to the child's needs for autonomy by exerting unwanted influence.

Parental overinvolvement during a child's third decade of life has been identified as a growing issue as more millennials delay taking on adult roles (Darlow, Norvilitis, \& Schuetze, 2017). Specifically, helicopter parenting has recently been recognized as a unique form of parental control during emerging adulthood with implications of inhibiting the child's growth and restricting opportunities to develop skills (Padilla-Walker \& Nelson, 2012). Although popular media has often painted caricatures of helicopter parents as overinvolved but loving parents who mean well despite their hovering behavior, research studies have found little evidence that helicopter parenting is associated with well-intentioned, warm parenting (e.g., Nelson, Padilla-Walker, \& Nielson, 2015). However, existing research has not considered variability in helicopter

'Brigham Young University, Provo, UT, USA

Corresponding Author:

Laura Padilla-Walker, Phd, Brigham Young University, 207I JFSB, Provo, UT 84602, USA.

Email: laura_walker@byu.edu 
parents by exploring helicopter parenting that co-occurs with other adaptive and maladaptive aspects of parenting.

Moreover, though the media has depicted helicopter parenting to be a central feature of parenting in emerging adulthood, that helicopter parenting is the norm may be an overstatement since only a small portion of parents even engage in highly controlling parenting (Nelson, Padilla-Walker, Christensen, Evans, \& Carroll, 2011). Rather, helicopter parenting as a distinct tactic of parental overinvolvement may be best understood in conjunction with other more prominent parenting approaches. Examining different parenting contexts in which helicopter parenting operates may provide information about how helicopter parenting might function as a means for support for some individuals and a means for control for others. Thus, the purpose of this study was to determine whether and how different groups of parents utilize helicopter parenting in combination with parental psychological control and parental warmth and to explore how these configurations of parenting are differentially associated with child outcomes.

\section{Helicopter Parenting}

Helicopter parenting is a unique form of control characterized by parents making important decisions for their child and trying to solve problems that their child could reasonably solve themselves (Hunt, 2008), such as monitoring school work or solving roommate problems (Schiffrin et al., 2014). Although there is overlap, helicopter parenting has been found to be meaningfully distinct from behavioral control and psychological control (Padilla-Walker \& Nelson, 2012) and is not correlated (Nelson et al., 2015) or is negatively correlated (Luebbe et al., 2016) with parental warmth. That being said, recent research suggests that different types of helicopter parenting may exist that are paired with other aspects of parenting and may be differentially effective for children. For example, Luebbe and colleagues (2016) found evidence for three subscales of helicopter parenting, one of which (autonomy limiting) was negatively associated with parental care and positively associated with parental control and another of which (information seeking) was associated with higher parental care but not associated with control. Another study sought to explore the relations between helicopter parenting and child outcomes when helicopter parenting was used in the context of parental warmth and when it was not (Nelson et al., 2015). These authors found that helicopter parenting in the absence of parental warmth was consistently associated with negative child outcomes (e.g., lower self-worth, higher risk behaviors), but findings were less consistent in the context of high parental warmth.

Taken together, these studies raise questions about whether different types of helicopter parents exist and if helicopter parenting paired with other aspects of parenting (e.g., control) might be more damaging than when paired with others (e.g., warmth). However, all the research to date on helicopter parenting has taken a variable-centered approach, assuming homogeneity in the population of interest. In other words, variable-centered approaches (such as regression analysis) focus on associations between variables and consider associations that are similar in all group members (Laursen \& Hoff, 2006). In relation to the current topic, variable-centered approaches might consider average levels of helicopter parenting, controlling parenting, and parental warmth in any given sample and explore questions related to predictors and outcomes of parenting independent of other aspects of parenting. In contrast, person-centered approaches (such as latent profile analysis [LPA]) focus on differences among individuals by categorizing individuals into groups or profiles (in this case, based on different aspects of parenting), so that between-group variability is more salient than within-group variability. Person-centered analyses identify groups or profiles of parents that are similar on a specified number of attributes. A person-centered approach will allow us to explore whether different groups of parents exist within our given sample and to interpret differences between these groups. This analysis will also allow us to consider the relative salience of helicopter parenting in defining parenting profiles compared to parental control and parental warmth. As noted previously, though helicopter parenting receives a great deal of attention in the popular media, research has not found it to be a common parenting behavior during the transition to adulthood compared to other forms of control such as psychological control (see Padilla-Walker \& Nelson, 2012).

\section{Parenting Profiles}

Helicopter parenting may be understood as providing intense support (e.g., financial, emotional, and academic; Fingerman, Cheng, Wesselmann, et al., 2012) motivated by love and concern for the child. Parents who want to prevent their children from making mistakes (i.e., preventative approach; Rousseau \& Scharf, 2017) may show their concern through overinvolvement. These parents may thus exhibit high levels of helicopter parenting and warmth/support in their attempts to provide resources to help navigate this period of life. For example, a study on clusters of parenting during emerging adulthood identified a group of mothers and fathers called "inconsistent" who reported high levels of both control and responsiveness (Nelson et al., 2011), though this study did not consider helicopter parenting.

In contrast, helicopter parenting could be understood as intense support as a means of controlling the child (PadillaWalker \& Nelson, 2012) or in response to parental anxiety (Segrin, Woszidlo, Givertz, Bauer, \& Taylor Murphy, 2012). Specifically, helicopter parenting may be coupled with psychological control (i.e., parenting that induces guilt, uses manipulation, and withdraws love as attempts to change children's behavior according to parents' desires; Barber \& Harmon, 2002). Parents who are anxious about distancing their emerging adult children tend to practice psychological control (Kins, Soenens, \& Beyers, 2011) and overprotective parenting (Katrijn, Soenens, Van Petegem, \& Kins, 2017). These parents may engage in helicopter parenting and psychological control 
in order to induce continued dependency. Consistent with this argument, several studies have found overlap between parental psychological control and helicopter parenting (Luebbe et al., 2016; Padilla-Walker \& Nelson, 2012). Thus, the first purpose of this study was to identify profiles of parents based on levels of helicopter parenting, parental warmth, and psychological control.

\section{Outcomes of Parenting Profiles}

The second purpose of the study was to explore child outcomes that may be associated with profiles of parenting. Research is well established regarding positive outcomes of parental warmth and support (e.g., Inguglia et al., 2016) and negative outcomes of parental psychological control during emerging adulthood (for a review, see Padilla-Walker \& Nelson, in press). Although helicopter parenting in general has been associated with negative outcomes (e.g., low self-efficacy, BradleyGeist \& Olson-Buchanan, 2014) during emerging adulthood, other studies have also found intense support to be linked with greater child life satisfaction and psychological adjustment (Fingerman, Cheng, Wesselmann, et al., 2012). Based on these findings, we expected helicopter parenting combined with psychological control to be negatively associated with child adjustment and the combination of parental warmth and helicopter parenting to be positively associated with adjustment.

Specifically, based on past findings highlighting their developmental significance, we examined school engagement, depression, and delinquency as outcomes of parenting profiles. As many emerging adults pursue postsecondary education, unwanted parental intervention and its influence in regard to academic performance has received considerable attention. Studies have found helicopter parenting to be negatively associated with academic performance such as school engagement (Darlow et al., 2017) via procrastination (Hong, Hwang, Kuo, $\&$ Hsu, 2015). Helicopter parenting has also been related to poor mental health (Reed, Duncan, Lucier-Greer, Fixelle, \& Ferraro, 2016). As depression has become a growing issue for emerging adults (Berry, 2004) due to the increased instabilities and uncertainties that children face during this time period (Kuwabara, Van Voorhees, Gollan, \& Alexander, 2007), we examined how different combinations of parenting would be associated with child depressive symptoms. Emerging adulthood is also characterized by a period of exploration and novelty seeking. With less social control and structure, emerging adults often engage in risky behaviors such as drug use and heavy drinking (White et al., 2006). While previous findings have indicated the adverse impact of parental psychological control on problem behaviors during emerging adulthood (Wagner \& Abaied, 2016), inconsistent findings regarding the outcomes of helicopter parenting further support the need for considering different profiles of helicopter parenting. For example, helicopter parenting has been both positively (Cui, Allen, Fincham, May, \& Love, 2018) and negatively (Earle \& LaBrie, 2016) associated with emerging adults' alcohol use. Thus, we expected that different profiles of helicopter parenting would have differential impact on delinquency and that the combinations of high parental psychological control and helicopter parenting would be associated with greater delinquency.

\section{Current Study}

As recent research has suggested the possibility of helicopter parenting as a unique form of parental control (Nelson et al., 2015), others have considered it an aspect of involvement (Luebbe et al., 2016) or intense support (e.g., financial, emotional, and academic; Fingerman, Cheng, Wesselmann, et al., 2012). The primary goal of this study was to use personcentered analyses to explore the ways in which helicopter parenting, parental psychological control, and parental warmth may co-occur in different groups of parents. It was hypothesized that some parents would engage in helicopter parenting combined with parental warmth, while others may exhibit high levels of both helicopter parenting and psychological control. We also explored whether parenting profiles differed as a function of child gender, living arrangement, and whether or not the emerging adult was in college. Given the exploratory nature of these analyses, we had no specific hypotheses in this regard.

Additionally, we explored how profiles of helicopter parenting would be differentially associated with school engagement, depression, and delinquency. Based on prior research on the outcomes of helicopter parenting (e.g., Darlow et al., 2017), parental warmth (e.g., Inguglia et al., 2016), and parental psychological control (e.g., Wagner \& Abaied, 2016), we hypothesized that helicopter parenting paired with warmth would be associated with adaptive outcomes, while helicopter parenting coupled with psychological control would be associated with reduced school engagement and higher depression and delinquency.

Children's perceptions of their parents' behaviors were used to measure helicopter parenting, parental psychological control, and parental warmth in this study. Child reports tend to more accurately capture actual parenting behaviors than parent reports, since parents have been found to depict their own parenting more favorably than do their partners or children (e.g., Bögels \& van Melick, 2004). Although child report of perceived parenting behaviors may reduce the bias of parents' socially desirable answers, children may display a heightened sensitivity to exertion of parental influence in emerging adulthood and thus may overestimate helicopter parenting. Nonetheless, child report may also provide information about the extent to which children perceive helicopter parenting to be intrusive. Given the increased need for autonomy during emerging adulthood, it was expected that children's reactions to the perceived threat of autonomy from parents would be expressed through their behavioral and emotional outcomes (i.e., school engagement, depression, and delinquency).

\section{Method}

\section{Participants and Procedures}

Participants included 458 emerging adults from a northwestern city in the United States who completed questionnaires 
at age 19 (51\% female, $33 \%$ from single-parent families). All emerging adults reported on their mother figure and the majority also reported on their father figure $(n=410)$. The majority (74\%) reported attending college or technical school, $16 \%$ indicated not attending college, and $6 \%$ reported being in high school or having just graduated from high school. In regard to living situation, $57 \%$ of the emerging adults indicated living with parents, $35 \%$ reported either living on campus or in an apartment/house with roommates, and 4\% indicated living with a romantic partner. In terms of ethnicity, $67 \%$ of participants were European American, 11\% were African American, and 22\% were multiethnic or other ethnicities. Regarding family income, $18 \%$ reported a family income less than US $\$ 40,000$ per year, $48 \%$ made between US $\$ 40,000$ and US $\$ 100,000$ a year, and $34 \%$ made more than US $\$ 100,000$ per year.

Once institutional review board approval was obtained from the sponsoring university (Protocol number F060311, Flourishing Families Project), data were collected each year beginning the first week of May, and longitudinal retention rate across waves was $90 \%$. For the first five waves of the study, the questionnaires were administered in the family home, Waves 6 through 10 were collected using an online survey platform (Qualtrics). Helicopter parenting items were not added to the data set until Wave 8. As each wave of data included an age range of 4 years, the data for this study were restructured by age to examine helicopter parenting profiles when emerging adult children were 19 years old, so that they would have transitioned out of high school into college or work.

\section{Measures}

Helicopter parenting. Emerging adults reported on helicopter parenting using a 5-item Helicopter Parenting Scale asking about the degree to which mothers and fathers made important decisions for their children (Padilla-Walker \& Nelson, 2012). Children answered questions on a 5-point scale ranging from 1 (not at all like her) to 5 (a lot like her). Sample questions consisted of "my parent intervenes in settling disputes with my roommates or friends" and "my parent solves any crisis or problem I might have" $(\alpha=.81, .83)$.

Parental warmth. Emerging adult children reported on their mothers' and fathers' warmth using the 5-item warmth/support subscale of the Parenting Styles and Dimensions Questionnaire-Short Version (Robinson, Mandleco, Olsen, \& Hart, 2001). Questions included behaviors indicative of warmth such as "My mother/father is responsive to my feelings and needs" $(\alpha=.89, .87)$. Responses ranged from 1 (never) to 5 (always), with higher scores representing greater maternal and paternal warmth.

Parental psychological control. Maternal and paternal psychological control were assessed using the 8-item Psychological Control Scale (Barber, 1996). Children answered how true items were for their parents. Sample items included "my parent interrupts me" and "my parent will avoid looking at me when I have disappointed her or him." Responses ranged from 1 (never) to 5 (very often) with higher scores indicating a greater degree of maternal and paternal psychological control $(\alpha=.90, .91)$.

School engagement. Emerging adults reported on their own levels of behavioral functioning at school based on a 10 -item modified version of a School Engagement Scale (Fredricks, Blumenfield, \& Paris, 2004). Sample items included, "I pay attention in class" and "I am interested in the work at school" $(\alpha=.83)$. Responses ranged from 1 (strongly disagree) to 5 (strongly agree), with higher scores indicating greater school engagement.

Delinquency. Child delinquency was measured using 9 items (Barber, Stolz, \& Olsen, 2005) including "I lie or cheat" and "I use alcohol or drugs." Participants were asked to rate how true each statement was about them, which responses ranging from 0 (not true) to 2 (often true). Higher scores represented higher levels of delinquent behavior $(\alpha=.72)$.

Depression. Child depression was assessed using the 20-item self-report CES-DC (Weissman, Orvaschel, \& Padian, 1980). Participants responded by rating the degree to which they have experienced each item in the past week, with a Likert-type scale ranging from 1 (not at all) to 4 (a lot). Sample items included, "I was bothered by things that usually don't bother me," with higher scores indicating greater depressive symptoms $(\alpha=.92)$.

\section{Data Analysis Plan}

LPA was conducted using Mplus 8.0 to identify groups of parents who might be different on levels of helicopter parenting, warmth, and control. Defaults were used in regard to variances and covariances across profiles. To determine the profile solution, we began with one profile and added profiles incrementally until there was no further improvement or profile sizes became too small to interpret. To compare the models, the following standard fit indices were evaluated. Lowest values of the Akaike information criterion (AIC), the Bayesian information criterion (BIC), the sample size-adjusted Bayesian information criterion (SSABIC) indicated the best fit (Burnham \& Anderson, 2004), with the SSABIC adjusting for the sample size (Sclove, 1987). The Vuong-Lo-Mendell-Rubin test (VLMR) and the Lo-Mendell-Rubin (LMR) adjusted likelihood ratio compared two models and provided significance ( $p$ value) of model fit with one additional profile (Lo, Mendell, \& Rubin, 2001). Entropy was also considered in order to evaluate the quality of discrimination among latent groups, with values closer to 1 representing better classification of cases (Ramaswamy, DeSarbo, Reibstein, \& Robinson, 1993). The profile solution was selected based on the goodness of fit and parsimony. After profile extraction, the R3step procedure was 
Table I. Correlations and Descriptive Statistics of All Study Variables.

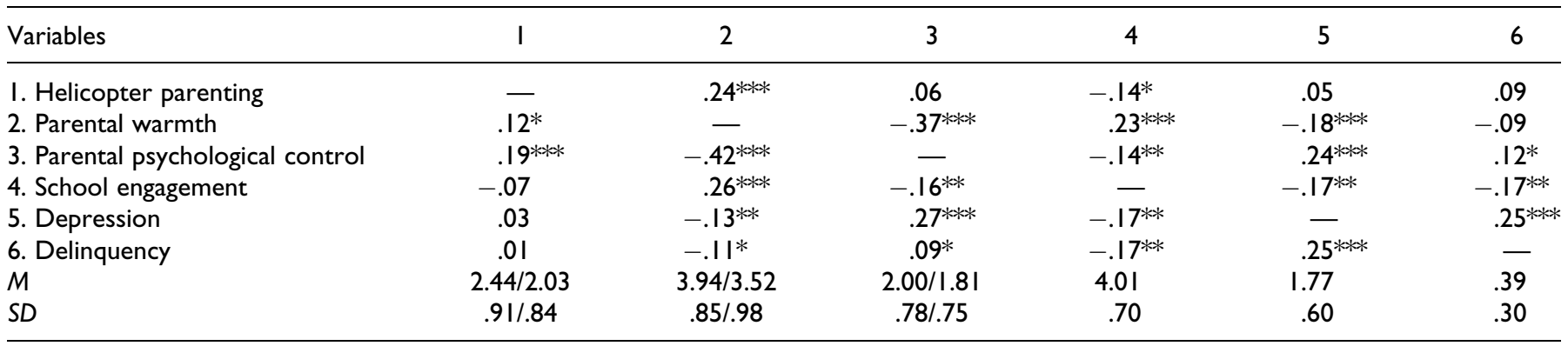

Note. All correlations below the diagonal are for mothers and above the diagonal are for fathers. Means and standard deviations before the slash indicate reports of mothers and after the slash are for fathers.

$* p<.05 . * * p .01 . * * * p<.001$.

Table 2. Relative Model Fit by Number of Latent Profiles for Mothers.

\begin{tabular}{|c|c|c|c|c|c|c|c|}
\hline Profiles & Profile Percentage & $\mathrm{AIC}$ & $\mathrm{BIC}$ & SSABIC & LMR & VLMR & Entropy \\
\hline I & $100(n=458)$ & $3,194.46$ & $3,219.22$ & $3,200.17$ & - & - & - \\
\hline 2 & 79,21 & $3,042.60$ & $3,083.86$ & $3,052.13$ & $p<.001$ & $p<.001$ & .82 \\
\hline 4 & $55,3,29,13$ & $2,941.61$ & $3,015.89$ & $2,958.77$ & $p=.16$ & $p=.17$ & .81 \\
\hline 5 & $52,30,5,3,10$ & $2,924.54$ & $3,015.33$ & $2,945.5 I$ & $p=.35$ & $p=.36$ & .83 \\
\hline
\end{tabular}

Note. Information criteria values in boldface represent the best fitting profile. AIC = Akaike information criterion; BIC = Bayesian information criterion; SSABIC $=$ sample size-adjusted Bayesian information criterion; LMR = Lo-Mendell-Rubin; VLMR = Vuong-Lo-Mendell-Rubin.

used to explore likely profile membership based on child gender, college attendance, and living arrangement and the du3step auxiliary procedure was performed to explore differences in profile means based on outcome variables (Asparouhov \& Muthén, 2014). Less than $5 \%$ of the data were missing and were considered to be missing completely at random (Little's Missing Completely at Random test: $\left.\chi^{2}=3.94, p=.139\right)$, and the full information maximum likelihood feature was applied during LPA.

\section{Results}

Descriptive statistics and correlations between all study variables are presented in Table 1. We acknowledge that all parenting variables represent emerging adult children's perceptions of parenting. Notably, helicopter parenting was positively correlated with parental warmth, while psychological control was negatively correlated with parental warmth for both mothers and fathers. Maternal helicopter parenting was also positively correlated with maternal psychological control, but paternal helicopter parenting was not. In addition, helicopter parenting was generally not correlated with the outcome variables, while other parenting variables were correlated with the outcomes in the expected direction.

In order to make comparisons between children's perceptions of mothers and fathers, measurement invariance for child reports of mothers' and fathers' helicopter parenting, parental warmth, and parental psychological control was tested using the Wald's $\chi^{2}$ difference test for parameter constraints. The test was performed sequentially at the configural, metric, and strict invariance levels (Vandenberg, \& Lance, 2000). Constraining the factor loadings to be equal across perceptions of maternal and paternal parenting yielded nonsignificant $\chi^{2}$ values for helicopter parenting (Wald test $=2.09, p=.719$ ) and parentalwarmth (Wald test $=4.13, p=.390$ ). Constraining the factor loading and intercepts produced significant Wald values, so configural and metric invariance were achieved for helicopter parenting and parental warmth. Regarding parental psychological control, factor loadings showed equality for 6 of the 8 items across mothers and fathers; thus, partial metric invariance was established. The 2 items that did not show metric equivalence on the factor loadings included, "My parent will avoid looking at me when I have disappointed her/him" and "If I have hurt her or his feelings, my parent stops talking to me until I please her/him again." Based on these analyses, we felt confident that we were measuring similar constructs for mothers and fathers.

\section{LPA}

The latent profiles were identified using helicopter parenting, parental warmth, and parental psychological control, with separate models for mothers and fathers. For the mother model (see Table 2 for fit indices), fit statistics suggested improvement from one to two profiles and from two to three profiles. Although AIC, BIC, and SSABIC continued to decrease for the four and five profile models, they did so incrementally and the LMR and VLMR showed no significant improvement in 
Table 3. Relative Model Fit by Number of Latent Profiles for Fathers.

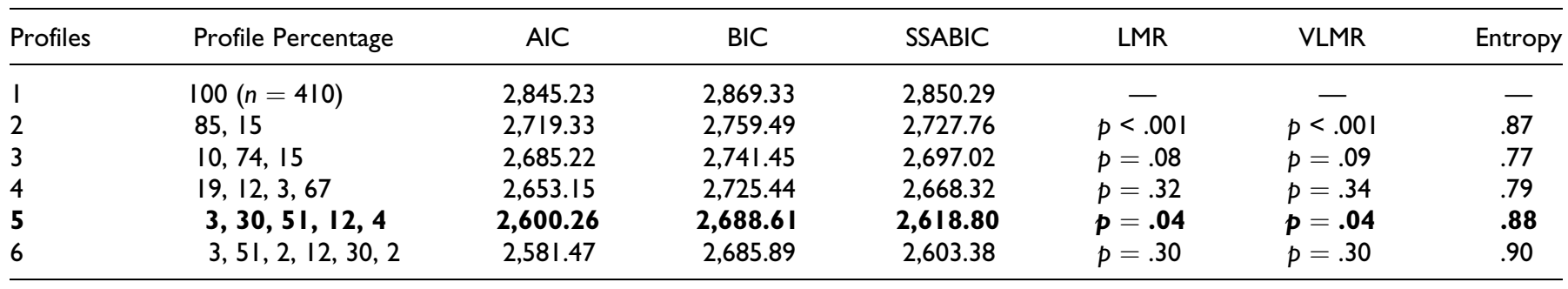

Note. Information criteria values in boldface represent the best fitting profile. AIC $=$ Akaike information criterion; $\mathrm{BIC}=\mathrm{Bayesian}$ information criterion; SSABIC $=$ sample size-adjusted Bayesian information criterion; LMR = Lo-Mendell-Rubin; VLMR = Vuong-Lo-Mendell-Rubin.

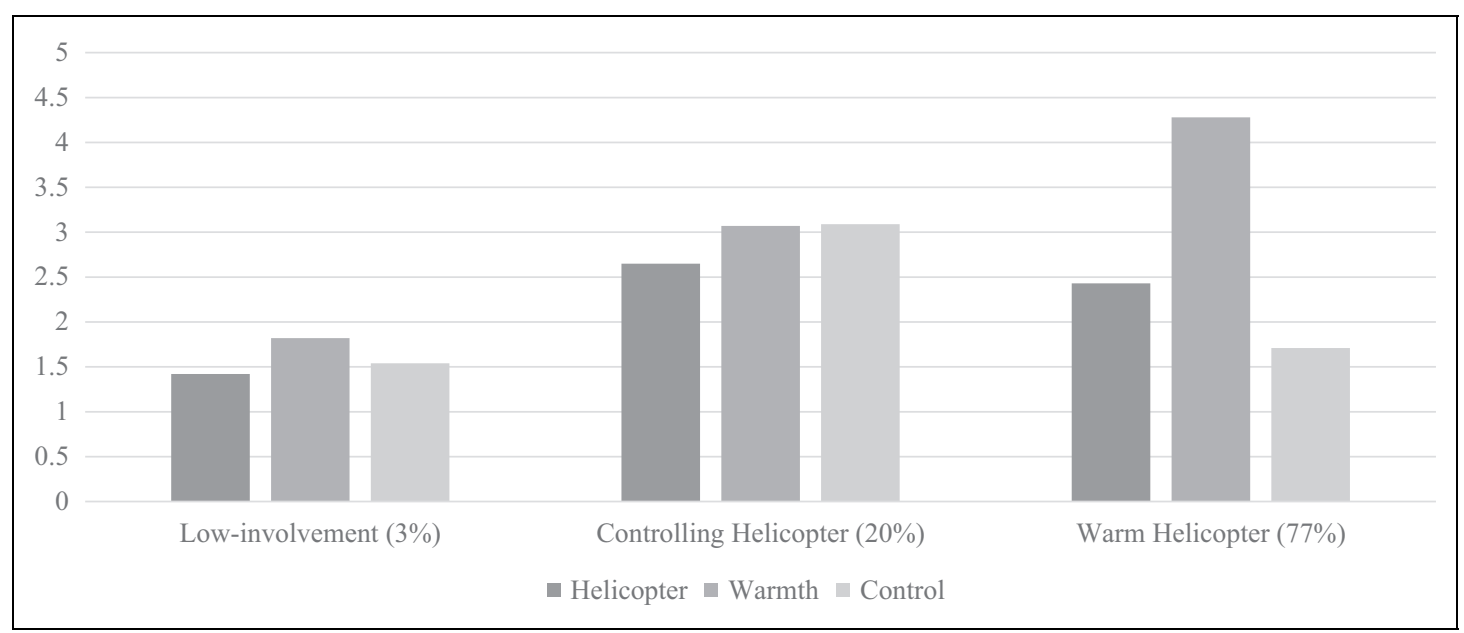

Figure I. Pattern of mean scores on maternal helicopter parenting, warmth, and psychological control as a function of latent profile. Note: All variables were on a I-5 scale.

moving from three to four profiles. Based on these fit statistics, we opted to interpret the three-profile solution for mothers. For the father model (see Table 3 for fit indices), fit statistics suggested improvement from one to two profiles, but the LMR and VLMR decrease in fit from the two to three profile and three to four profile solutions. However, from four to five profiles, the AIC, BIC, and SSABIC decreased more markedly and the LMR and VLMR suggested an increase in model fit from four to five profiles. Thus, we opted to interpret the five-profile solution for fathers. We noted the existence of small profile sizes for both the mother and father models, so encourage caution when interpreting these groups. Despite their size, we opted to retain them in our interpretation because they seemed theoretically relevant and were consistent between mothers and fathers.

Before we interpreted profiles, we explored entropy to see which aspect of parenting was distinguishing between profiles the most, and we explored whether helicopter parenting was significantly different across different profiles using model constraints in Mplus. For the mother model, these analyses suggested that psychological control and warmth were contributing most to distinguishing between profiles (.72 for each) followed by helicopter parenting (.43). Constraints suggested that those in the first profile for mothers had lower levels of helicopter parenting than the other two profiles, which did not differ from one another.

For the father model, these analyses suggested that psychological control was contributing most to distinguishing between profiles (.81) followed by warmth (.39) and helicopter parenting (.26). Constraints suggested that those in the first profile for fathers had lower levels of helicopter parenting than any other profile, but none of the other profiles differed significantly in their levels of helicopter parenting. With these analyses in mind, we interpreted the different profiles.

The three-profile solution for mothers is depicted in Figure 1 and the five-profile solution for fathers in Figure 2. Three of the five profiles were very similar for mothers and fathers. The first profile ( $3 \%$ of both mothers and fathers) consisted of parents who scored below the mean on all parenting variables, so we called this group "low-involvement" parents. The second profile ( $20 \%$ of mothers, $12 \%$ of fathers) had similar levels of warmth and control, but these levels represented control that was above the mean and warmth that was below the mean, with slightly above average levels of helicopter parenting, so we called this group "controlling helicopter" parents. The second profile ( $77 \%$ of mothers, $50 \%$ of fathers) had levels of warmth above the mean and psychological control 


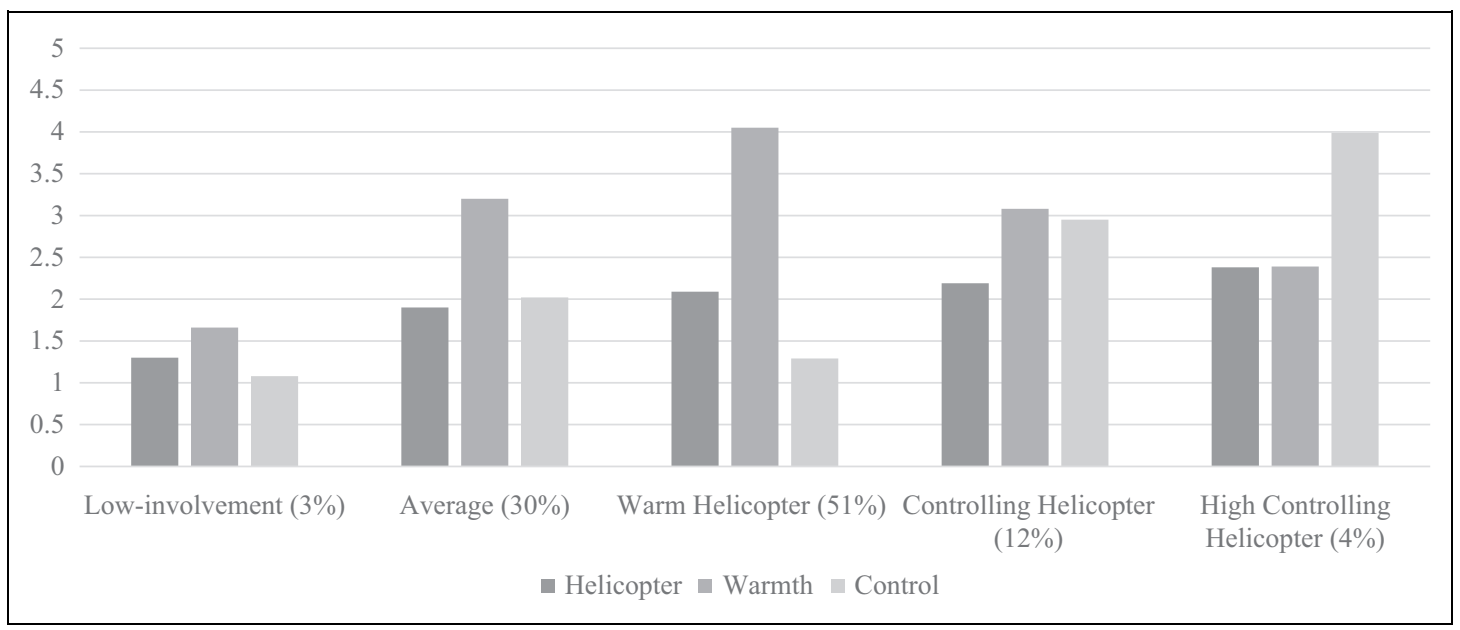

Figure 2. Pattern of mean scores on paternal helicopter parenting, warmth, and psychological control as a function of latent profiles. Note: All variables were on a I-5 scale.

Table 4. Test of Mean Differences Across Outcome Variables as a Function of Maternal Profiles.

\begin{tabular}{lccccc}
\hline Variables & Profile I Low Involvement & Profile 2 Controlling Helicopter & Profile 3 Warm Helicopter & Overall $\chi^{2}$ & $p$ Value \\
\hline School engagement & $3.29(.30)_{\mathrm{a}}$ & $3.72(.13)_{\mathrm{a}}$ & $4.11(.05)_{\mathrm{b}}$ & 12.75 \\
Depression & $1.59(.04)_{\mathrm{a}}$ & $2.13(.09)_{\mathrm{b}}$ & .002 \\
Delinquency & $0.50(.10)$ & $0.47(.06)$ & $1.67(.04)_{\mathrm{a}}$ & 17.80 & .001 \\
\hline
\end{tabular}

Note. Standard errors presented in parentheses. Means with differing subscripts are statistically different at $p<.05$.

Table 5. Test of Mean Differences Across Outcome Variables as a Function of Paternal Profiles.

\begin{tabular}{|c|c|c|c|c|c|c|c|}
\hline Variables & $\begin{array}{c}\text { Profile I } \\
\text { Low Involvement }\end{array}$ & $\begin{array}{l}\text { Profile } 2 \\
\text { Average }\end{array}$ & $\begin{array}{c}\text { Profile } 3 \\
\text { Warm Helicopter }\end{array}$ & $\begin{array}{c}\text { Profile } 4 \\
\text { Controlling Helicopter }\end{array}$ & $\begin{array}{c}\text { Profile } 5 \text { High } \\
\text { Controlling Helicopter }\end{array}$ & $\begin{array}{c}\text { Overall } \\
\chi^{2}\end{array}$ & $p$ Value \\
\hline $\begin{array}{l}\text { School } \\
\text { engagement }\end{array}$ & $3.17(.30)_{\mathrm{a}}$ & $3.91(.08)_{\mathrm{b}}$ & $4.18(.07)_{c}$ & $3.99(.10)_{b c}$ & $3.26(.24)_{\mathrm{a}}$ & 19.99 & .001 \\
\hline Depression & $2.37(.27)_{\mathrm{a}}$ & $1.82(.07)_{\mathrm{b}}$ & $1.60(.07)_{c}$ & $1.95(.09)_{\mathrm{ab}}$ & $2.39(.21)_{\mathrm{a}}$ & 20.93 & .001 \\
\hline Delinquency & $0.83(.12)_{\mathrm{a}}$ & $0.38(.04)_{\mathrm{b}}$ & $0.34(.03)_{\mathrm{b}}$ & $0.45(.05)_{c}$ & $0.53(.09)_{\mathrm{c}}$ & 18.97 & .001 \\
\hline
\end{tabular}

Note. Standard errors presented in parentheses. Means with differing subscripts are statistically different at $p<.05$.

below the mean, with levels of helicopter parenting right at mean levels, so we called this group "warm helicopter" parents. Two additional profiles were identified for fathers. One $(30 \%)$ had levels of all three parenting variables right around their respective means. This group really did not stand out in any way, so we called this group "average" fathers. Another small group (4\%) displayed very high levels of control and low levels of warmth, with helicopter parenting around the mean, so we called this group "high controlling helicopter" fathers.

After establishing and interpreting profiles, we used logistical regression analyses to determine if child gender, whether emerging adults were in college, and whether they were living with their parents predicted profile membership. None of the pairwise comparisons for living arrangement or child gender were statistically significant, but attending college was associated with parenting profiles. For the mother model, those attending college were less likely to perceive their parents as warm helicopter parents compared to controlling helicopter parents (odds ratio $[O R]=-.81, S E=.34, p=.018$ ). For the father model, those attending college were less likely to perceive their parents as warm helicopter parents compared to average parents $(O R=-.77, S E=.31, p=.012)$ and more likely to perceive their parents as high controlling helicopter parents compared to warm helicopter parents $(O R=1.13$, $S E=.40, p=.005)$.

\section{Association of Latent Profiles With Child Adjustment Outcomes}

We then evaluated mean differences between profiles on the basis of child school engagement (only for those attending 
school, which excluded about $16 \%$ of the sample), depression, and delinquency for both mother (see Table 4) and father (see Table 5) models. For mothers, results indicated that warm helicopter mothers had children with the highest level of school engagement, whereas controlling helicopter mothers had children with the highest levels of depressive symptoms. There was no difference between the warm helicopter and low involvement profiles on depressive symptoms and no difference between any profiles on delinquency. For fathers, results suggested that warm helicopter and average fathers had children with the lowest levels of depressive symptoms and delinquency. Warm helicopter fathers also had children with the highest levels of school engagement (no difference from controlling helicopter). School engagement was lowest and depressive symptoms and delinquency highest for high controlling helicopter and low involvement fathers.

\section{Discussion}

Although the media portrays helicopter parents as individuals who lovingly hover over their child to promote success, mounting research evidence is unclear on whether or not helicopter parenting co-occurs with warmth or is more indicative of parental control. Recent research suggests that some forms of helicopter parenting are maladaptive while others less so (Luebbe et al., 2016). However, all research of which we are aware has used a variable-centered approach, which does not allow for heterogeneity in parenting. Thus, the purpose of the current study was to use a person-centered approach to assess whether different profiles of helicopter parents might be identified and how these different profiles would be associated with child outcomes during emerging adulthood. Findings were somewhat consistent with hypotheses suggesting that parents may use helicopter parenting in concert with a variety of other aspects of parenting and that these combinations are associated differentially with child outcomes.

\section{Profiles of Helicopter Parents}

Addressing our first research question, we found evidence of three different parenting profiles for mothers and five for fathers, as reported by emerging adult children. The largest group of both mothers (77\%) and fathers (50\%) were those that displayed above average levels of warmth and average levels of helicopter parenting or "warm helicopter parents." While this suggests that a large portion of parents are characterized as warm while also displaying at least average levels of helicopter parenting, it is of note that levels of helicopter parenting were not high in this or any profile. Thus, while one may be tempted to suggest this profile is consistent with the picture painted by the media of parents who are intensely overinvolved but also very loving, we feel this would be an overstatement and argue that levels of both warmth and helicopter parenting in this profile are at best, moderate. Indeed, rather than being helicopter parents who are warm, this group of parents might be better characterized as warm parents who occasionally employ helicopter parenting or, in other words, step in to assist their children at an average (which is relatively low) level.

It is also of note that while profiles did not differ as a function of child gender or living arrangement, we did find that children were less likely to perceive their mothers and fathers as warm helicopter parents (compared to controlling profiles) if the child was attending college. It is possible that children who are attending college perceive their parents as less warm and more controlling because parents may be providing financial support for college that allows an increased level of control or leverage over the child (Padilla-Walker et al., 2014; Padilla-Walker, Nelson, \& Carroll, 2012). It is clearly important for future research to continue to consider both college and noncollege samples as the role of parenting is explored during the transition to adulthood.

A second group that consisted of both mothers $(20 \%)$ and fathers $(12 \%)$ was characterized by quite high levels of control, low levels of warmth, and average levels of helicopter parenting. This group is more consistent with conceptualizations by researchers of parents who use helicopter parenting as a form of control (Padilla-Walker \& Nelson, 2012) and who use what might be considered autonomy limiting helicopter parenting (Luebbe et al., 2016), though it is of note that this group of parents did not make up the majority. Again, this suggests that the perception of controlling helicopter parents as the rule (rather than the exception) would be overblown. It does, however, suggest a group of parents who appear to employ a number of forms of control (psychological, helicopter) to limit their emerging adult children's autonomy. Hence, it may not be accurate to label these types of parents as "helicopter parents," specifically, but rather controlling parents more generally.

A final group of parents that was identified for both mothers and fathers (3\% for both) was a very small number of parents who scored low on all three aspects of parenting, suggesting low levels of involvement overall. This is consistent with research on parents of emerging adults suggesting that for a minority of young people, parents disengage significantly (at least from the child's perspective) once their children leave the parental home. Whereas this group was very small in the current study, other studies have found close to $20 \%$ of mothers and fathers classified as having low levels of involvement in a variety of aspects of parenting (e.g., control, punishment, knowledge, warmth, autonomy; Nelson et al., 2011). It is possible that in the 7 years, since Nelson et al. conducted their study, fewer parents are uninvolved, but given the relatively high income sample used in the current study and the all-college-student sample used by Nelson and colleagues, additional research is certainly needed to more clearly understand the prevalence of low levels of parental involvement during emerging adulthood. This is especially important given research suggesting that emerging adults whose parents are involved do better in a variety of ways including having fewer sexual risks (Wetherill, Neal, \& Fromme, 2010) and delinquent acts (Johnson, Giordano, 
Manning, \& Longmore, 2011), as well as demonstrating greater academic (Bronte-Tinkew, Scott, \& Lilja, 2010) and career (Stringer \& Kerpelman, 2010) success.

\section{Unique Profiles for Fathers}

Whereas fathers displayed all three profiles that mothers displayed, there were also an additional two profiles that were unique for fathers. The first (4\%) consisted of a group much like controlling helicopter parents, but with higher levels of control and lower levels of warmth, we referred to them as high controlling helicopter parents. Another sizable group was found for fathers $(30 \%)$ that we referred to as "average" because their scores on all three aspects of parenting were right around mean levels. Interestingly, this is similar to a group of fathers (but not mothers) that was found in another personcentered study of parenting during emerging adulthood. Nelson and colleagues (2011) found that nearly $50 \%$ of fathers could be classified as average, with scores near the mean on a variety of aspects of parenting. The identification of different profiles for fathers and mothers is consistent with research suggesting that maternal and paternal parenting may look different (Möller, Nikolić, Majdandžić, \& Bögels, 2016; Videon, 2005) and should be examined separately (Dyer, Day, \& Harper, 2014). These findings are certainly in need of replication, but given the large number of studies that do not consider paternal parenting, especially during emerging adulthood, this is an important avenue for future research.

It appears that a small group of fathers may be characterized by very high levels of control but also that a significant portion of fathers are relatively "average" in their levels of parenting. This may reflect messages that fathers receive regarding their auxiliary (Schmitz, 2016), incompetent (Fagan \& Barnett, 2003), or ambiguous (Castelain-Meunier, 2002) parenting positions compared to mothers. A recent study found that fathers report spending more time with their children and being more involved than in the past but also found that aspects of traditional masculinity were associated with lower positive father involvement and higher levels of harsh discipline (Petts, Shafer, \& Essig, 2018). These findings may inform the current study and raise the possibility that while fathers in general may report above average levels of parenting behavior (about $50 \%$ of our sample), the current findings identify at least a sizable minority of fathers who continue to be perceived as either only marginally involved or controlling (which may represent fathers who are high on traditional masculinity or have received negative messages of fatherhood). Given that parents of emerging adults may feel less confident and clear of their roles once children leave the home, it is possible that this ambiguity is even more pronounced for fathers. Clearly, future research is needed on fathering during emerging adulthood.

\section{The Salience of Helicopter Parenting}

Another contribution of the current study is that, despite our focus on helicopter parenting, this construct was clearly not the distinguishing factor in parenting profiles for either mothers or fathers. Rather, control was the clearest factor for fathers and both warmth and control for mothers in distinguishing between profiles. In addition, other than the low-involved profile, none of the other profiles differed in their levels of helicopter parenting, suggesting that for most parents of emerging adults, this approach to parenting (i.e., overinvolvement) is not terribly prevalent or distinguishing or is simply a part of a larger overall approach to parenting that centers on controlling or supporting their emerging adult children.

Research has certainly found helicopter parenting to be directly associated with negative outcomes during emerging adulthood, such as low academic achievement (Schiffrin \& Liss, 2017), low self-efficacy (Givertz \& Segrin, 2014), internalizing problems (LeMoyne \& Buchanan, 2011), and negative peer relationships (van Ingen et al., 2015). However, the current study suggests that average levels of helicopter parenting (which are quite low) paired with above average levels of warmth are associated with positive outcomes in emerging adult children. For example, warm helicopter parents had children with the highest levels of school engagement (for mother and father profiles) and the lowest levels of depression and delinquency (for father profiles, though it is of note that these outcomes did not differ from average fathers). Taken together with past research, we would not go as far as to suggest that warm helicopter parenting is adaptive, as it is not associated as consistently with positive outcomes as is authoritative parenting (Nelson et al., 2011) or autonomous parenting (Kouros, Pruitt, Ekas, Kiriaki, \& Sunderland, 2017). However, perhaps building upon research that found fewer risk behaviors for emerging adults whose parents were high on helicopter parenting but also high on warmth (Nelson et al., 2015), the current study suggests that average levels of helicopter parenting that is well meaning and motivated by love for the child is not as maladaptive as is helicopter parenting motivated or paired with control. Indeed, consistent with studies that have found controlling parenting to be particularly damaging during emerging adulthood (e.g., Liga et al., 2017) and low-involved parenting to be maladaptive at all ages (e.g., Church et al., 2015), the current study found that controlling helicopter parents, low-involved parents, and high controlling helicopter fathers had children with higher levels of depressive symptoms and delinquency compared to other profiles. These findings suggest that helicopter parenting paired with control, while less common than helicopter parenting paired with warmth, may be considerably more detrimental to children. However, we would note that these negative effects are likely more due to control, generally, than they are to helicopter parenting, specifically, given the salience of control and the degree to which it distinguished between profiles.

\section{Limitations and Conclusions}

Although the current study adds meaningfully to the literature on parenting emerging adults and has the clear strength of 
including both college and noncollege students, it is not without limitations. Namely, it is based on cross-sectional data from a relatively homogeneous sample. Although cross-sectional data are appropriate for our main research question, future research should explore whether these parenting profiles change developmentally and how they might impact children's behavior over time. In the current study, we could not determine direction of effects, so it is also possible that children's behavior influences helicopter parenting, which should be explored. Furthermore, given the focus on different profiles of parents, a more diverse sample might have included additional groups of parents who use helicopter parenting, warmth, and control in different ways. Another limitation is that all measures were self-reported from emerging adults. Although emerging adults provide an important perspective on parenting, future research should try to obtain additional reports on children's behaviors to reduce bias. Finally, whereas one of the strengths of our study was that different profiles were explored for mothers and fathers, future research would benefit from understanding outcomes for emerging adults who have parents with similar or different profiles of parenting. For example, did children who perceived their mother to be a warm helicopter parenting also perceive their father similarly? This is an important avenue for future research.

Despite these limitations, this study suggests that helicopter parenting is likely one behavior that occurs within an assortment of other parenting behaviors, and the impact depends somewhat on these other, perhaps more prominent, aspects of parenting. That being said, we did find evidence for a number of different profiles of parents who use helicopter parenting, which suggests value in considering co-occurrence of this construct with other aspects of parenting and using personcentered approaches when exploring parenting during emerging adulthood. Furthermore, no profiles were identified where parents displayed high levels of helicopter parenting. Indeed, the most common profile was when average levels of helicopter parenting were paired with warmth and low control. This suggests the caricature of parents who are constantly hovering over their children, calling professors and intervening with supervisors, may not be realistic. Findings also suggested that relatively low levels of helicopter parenting may be less harmful (and in some cases even helpful) when paired with parental warmth and low levels of control but may be considerably more harmful when paired with high levels of control. These findings have important implications for parents and educators, as well as those who work with college students or large groups of emerging adults and their parents. We have much yet to learn about helicopter parenting and how it influences children's development long term, but for the vast majority of emerging adults in the current sample, helicopter parenting was not the driving factor in associated risk.

\section{Author Contributions}

L. Padilla-Walker contributed to conception, design, acquisition, analysis, and interpretation; drafted the manuscript; critically revised the manuscript; gave final approval; and agreed to be accountable for all aspects of work ensuring integrity and accuracy. L. Nelson contributed to conception, design, and acquisition; select the item; critically revised the manuscript; gave final approval; and agreed to be accountable for all aspects of work ensuring integrity and accuracy. D. Son contributed to conception, analysis, and interpretation; drafted the manuscript; critically revised the manuscript; gave final approval; and agreed to be accountable for all aspects of work ensuring integrity and accuracy.

\section{Declaration of Conflicting Interests}

The authors declared no potential conflicts of interest with respect to the research, authorship, and/or publication of this article.

\section{Funding}

The authors received no financial support for the research, authorship, and/or publication of this article.

\section{Open Practices}

Data and materials for this study have not been made publicly available. The design and analysis plans were not preregistered.

\section{References}

Aquilino, W. S. (1997). From adolescent to young adult: A prospective study of parent-child relations during the transition to adulthood. Journal of Marriage and the Family, 53, 670-686. doi:10. $2307 / 353953$

Arnett, J. J. (2000). Emerging adulthood: A theory of development from the late teens through the twenties. American Psychologist, 55, 469-480. doi:10.1037/0003-066X.55.5.469

Arnett, J. J., \& Schwab, J. (2012). The Clark University poll of emerging adults: Thriving, struggling, and hopeful. Worcester, MA: Clark University.

Asparouhov, T., \& Muthén, B. (2014). Auxiliary variables in mixture modeling: Three-step approaches using M plus. Structural Equation Modeling: A Multidisciplinary Journal, 21, 329-341. doi:10. 1080/10705511.2014.915181

Barber, B. K. (1996). Parental psychological control: Revisiting a neglected construct. Child Development, 67, 3296-3319. doi:10.1111/j.1467-8624.1996.tb01915.x

Barber, B. K., \& Harmon, E. L. (2002). Violating the self: Parental psychological control of children and adolescents. In B. K. Barber (Ed.), Intrusive parenting. How psychological control affects children and adolescents (pp. 15-52). Washington, DC: American Psychological Association.

Barber, B. K., Stolz, H. E., \& Olsen, J. A. (2005). Parental support, psychological control, and behavioral control: Assessing relevance across time, culture, and method. Monographs of the Society for Research in Child Development, 70, 1-137. doi:10.1111/j.15405834.2005.00365.x

Berry, D. (2004). The relationship between depression and emerging adulthood: theory generation. Advances in Nursing Science, 27, 53-69.

Bögels, S. M., \& van Melick, M. (2004). The relationship between child-report, parent self-report, and partner report of perceived parental rearing behaviors and anxiety in children and parents. Personality and Individual Differences, 37, 1583-1596. doi:10.1016/ j.paid.2004.02.014 
Bradley-Geist, J., \& Olson-Buchanan, J. (2014). Helicopter parents: An examination of the correlates of over-parenting of college students. Education + Training, 56, 314-328. doi:10.1108/et-102012-0096

Bronte-Tinkew, J., Scott, M. E., \& Lilja, E. (2010). Single custodial fathers' involvement and parenting: Implications for outcomes in emerging adulthood. Journal of Marriage and Family, 72, 1107-1127. doi:10.1111/j.1741-3737.2010.00753.x

Burnham, K. P., \& Anderson, D. R. (2004). Multimodel inference: Understanding AIC and BIC in model selection. Sociological Methods \& Research, 33, 261-304. doi:10.1177/ 0049124104268644

Castelain-Meunier, C. (2002). The place of fatherhood and the parental role: Tensions, ambivalence and contradictions. Current Sociology, 50, 185-201. doi:10.1177/0011392102050002616

Church W. T. II, Jaggers, J. W., Tomek, S., Bolland, A. C., Bolland, K. A., Hooper, L. M., \& Bolland, J. M. (2015). Does permissive parenting relate to levels of delinquency? An examination of family management practices in low-income Black American families. Journal of Juvenile Justice, 4, 95-110.

Cui, M., Allen, J. W., Fincham, F. D., May, R. W., \& Love, H. (2018). Helicopter parenting, self-regulatory processes, and alcohol use among female college students. Journal of Adult Development, 26, 97-104.

Darlow, V., Norvilitis, J. M., \& Schuetze, P. (2017). The relationship between helicopter parenting and adjustment to college. Journal of Child and Family Studies, 26, 2291-2298. doi:10.1007/s10826017-0751-3

Dyer, W. J., Day, R. D., \& Harper, J. M. (2014). Father involvement: Identifying and predicting family members' shared and unique perceptions. Journal of Family Psychology, 28, 516-528. doi:10. $1037 / \mathrm{a} 0036903$

Earle, A. M., \& LaBrie, J. W. (2016). The upside of helicopter parenting: Engaging parents to reduce first-year student drinking. Journal of Student Affairs Research and Practice, 53, 319-330. doi:10.1080/19496591.2016.1165108

Fagan, J., \& Barnett, M. (2003). The relationship between maternal gatekeeping, paternal competence, mothers' attitudes about the father role, and father involvement. Journal of Family Issues, 24, 1020-1043. doi:10.1177/0192513x03256397

Fingerman, K. L., Cheng, Y. P., Wesselmann, E. D., Zarit, S., Furstenberg, F., \& Birditt, K. S. (2012). Helicopter parents and landing pad kids: Intense parental support of grown children. Journal of Marriage and Family, 74, 880-896. doi:10.1111/j.1741-3737. 2012.00987.x

Fingerman, K. L., \& Yahirun, J. J. (2015). Emerging adulthood in the context of family. In J. J. Arnett (Ed.), The Oxford handbook of emerging adulthood (pp. 163-176). New York, NY: Oxford University Press.

Fredricks, J. A., Blumenfeld, P. C., \& Paris, A. H. (2004). School engagement: Potential of the concept, state of the evidence. Review of Educational Research, 74, 59-109. doi:10.3102/ 00346543074001059

Givertz, M., \& Segrin, C. (2014). The association between overinvolved parenting and young adults' self-efficacy, psychological entitlement, and family communication. Communication Research, 41, 1111-1136. doi:10.1177/0093650212456392

Hair, E. C., Moore, K. A., Garrett, S. B., Ling, T., \& Cleveland, K. (2008). The continued importance of quality parent-adolescent relationships during late adolescence. Journal of Research on Adolescence, 18, 187-200. doi:10.1111/j.1532-7795.2008. 00556.x

Hong, J. C., Hwang, M. Y., Kuo, Y. C., \& Hsu, W. Y. (2015). Parental monitoring and helicopter parenting relevant to vocational student's procrastination and self-regulated learning. Learning and Individual Differences, 42, 139-146. doi:10.1016/j.lindif. 2015.08 .003

Hunt, J. (2008). Make room for daddy ... and mommy: Helicopter parents are here. The Journal of Academic Administration in Higher Education, 4, 9-11.

Inguglia, C., Ingoglia, S., Liga, F., Coco, A. L., Cricchio, M. G. L., Musso, P., ... Lim, H. J. (2016). Parenting dimensions and internalizing difficulties in Italian and US emerging adults: The intervening role of autonomy and relatedness. Journal of Child and Family Studies, 25, 419-431. doi:10.1007/s10826-0150228-1

Johnson, W. L., Giordano, P. C., Manning, W. D., \& Longmore, M. A. (2011). Parent-child relations and offending during young adulthood. Journal of Youth and Adolescence, 40, 786-799. doi:10.1007/s10964-010-9591-9

Katrijn, M. B., Soenens, B., Van Petegem, S., \& Kins, E. (2017). Searching for the roots of overprotective parenting in emerging adulthood: Investigating the link with parental attachment representations using an actor partner interdependence model (APIM). Journal of Child and Family Studies, 26, 2299-2310. doi:10.1007/s10826-017-0744-2

Kins, E., Soenens, B., \& Beyers, W. (2011). "Why do they have to grow up so fast?" Parental separation anxiety and emerging adults' pathology of separation-individuation. Journal of Clinical Psychology, 67, 647-664. doi:10.1002/jclp.20786

Koepke, S., \& Denissen, J. J. (2012). Dynamics of identity development and separation-individuation in parent-child relationships during adolescence and emerging adulthood-A conceptual integration. Developmental Review, 32, 67-88. doi:10.1016/j.dr.2012.01.001

Kouros, C. D., Pruitt, M. M., Ekas, N. V., Kiriaki, R., \& Sunderland, M. (2017). Helicopter parenting, autonomy support, and college students' mental health and well-being: The moderating role of sex and ethnicity. Journal of Child and Family Studies, 26, 939-949. doi:10.1007/s10826-016-0614-3

Kuwabara, S. A., Van Voorhees, B. W., Gollan, J. K., \& Alexander, G. C. (2007). A qualitative exploration of depression in emerging adulthood: Disorder, development, and social context. General Hospital Psychiatry, 29, 317-324. doi:10.1016/j.genhosppsych.2007.04.001

Laursen, B., \& Hoff, E. (2006). Person-centered and variable-centered approaches to longitudinal data. Merrill-Palmer Quaterly, 52, 377-389.

LeMoyne, T., \& Buchanan, T. (2011). Does "hovering” matter? Helicopter parenting and its effect on well-being. Sociological Spectrum, 31, 399-418. doi:10.1080/02732173.2011.574038

Liga, F., Ingoglia, S., Inguglia, C., Lo Coco, A., Lo Cricchio, M. G., Musso, P., ... Gutow, M. R. (2017). Associations among 
psychologically controlling parenting, autonomy, relatedness, and problem behaviors during emerging adulthood. The Journal of Psychology, 151, 393-415. doi:10.1080/00223980.2017.1305323

Lo, Y., Mendell, N. R., \& Rubin, D. B. (2001). Testing the number of components in a normal mixture. Biometrika, 88, 767-778. doi:10.1093/biomet/88.3.767

Luebbe, A. M., Mancini, K. J., Kiel, E. J., Spangler, B. R., Semlak, J. L., \& Fussner, L. M. (2016). Dimensionality of helicopter parenting and relations to emotional, decision-making, and academic functioning in emerging adults. Assessment, 25, 841-857.

Möller, E. L., Nikolić, M., Majdandžić, M., \& Bögels, S. M. (2016). Associations between maternal and paternal parenting behaviors, anxiety and its precursors in early childhood: A meta-analysis. Clinical Psychology Review, 45, 17-33. doi:10.1016/j.cpr.2016. 03.002

Nelson, L. J., \& Padilla-Walker, L. M. (2013). Flourishing and floundering in emerging adult college students. Emerging Adulthood, 1, 67-78. doi:10.1177/2167696812470938

Nelson, L. J., Padilla-Walker, L. M., Carroll, J. S., Madsen, S. D., Barry, C. M., \& Badger, S. (2007). "If you want me to treat you like an adult, start acting like one!" Comparing the criteria that emerging adults and their parents have for adulthood. Journal of Family Psychology, 21, 665-674. doi:10.1037/0893-3200.21.4.665

Nelson, L. J., Padilla-Walker, L. M., Christensen, K. J., Evans, C. A., \& Carroll, J. S. (2011). Parenting in emerging adulthood: An examination of parenting clusters and correlates. Journal of Youth and Adolescence, 40, 730-743. doi:10.1007/s10964-010-9584-8

Nelson, L. J., Padilla-Walker, L. M., \& Nielson, M. G. (2015). Is hovering smothering or loving? An examination of parental warmth as a moderator of relations between helicopter parenting and emerging adults' indices of adjustment. Emerging Adulthood, 3, 282-285. doi:10.1177/2167696815576458

Padilla-Walker, L. M., \& Nelson, L. J. (in press). Parenting emerging adults. In M. Bornstein (Ed.), The Handbook of Parenting.

Padilla-Walker, L. M., \& Nelson, L. J. (2012). Black hawk down? Establishing helicopter parenting as a distinct construct from other forms of parental control during emerging adulthood. Journal of Adolescence, 35, 1177-1190. doi:10.1016/j.adolescence. 2012.03.007

Padilla-Walker, L. M., Nelson, L. J., \& Carroll, J. S. (2012). Affording emerging adulthood: Parental financial assistance of college-aged children. Journal of Adult Development, 19, 50-58.

Padilla-Walker, L. M., Nelson, L. J., \& Knapp, D. J. (2014). "Because I'm still the parent, that's why!" Parental legitimate authority during emerging adulthood. Journal of Social and Personal Relationships, 31, 293-313. doi:10.1177/0265407513494949

Petts, R. J., Shafer, K. M., \& Essig, L. (2018). Does adherence to masculine norms shape fathering behavior? Journal of Marriage and Family, 80, 704-720. doi:10.1111/jomf.12476

Ramaswamy, V., DeSarbo, W. S., Reibstein, D. J., \& Robinson, W. T. (1993). An empirical pooling approach for estimating marketing mix elasticities with PIMS data. Marketing Science, 12, 103-124. doi:10.1287/mksc.12.1.103

Reed, K., Duncan, J. M., Lucier-Greer, M., Fixelle, C., \& Ferraro, A. J. (2016). Helicopter parenting and emerging adult selfefficacy: Implications for mental and physical health. Journal of Child and Family Studies, 25, 3136-3149. doi:10.1007/ s10826-016-0466-x

Robinson, C. C., Mandleco, B., Olsen, S. F., \& Hart, C. H. (2001). The Parenting Styles and Dimensions Questionnaire (PSDQ). In B. F. Perlmutter, J. Touliatos, \& G. W. Holden (Eds.), Handbook of family measurement techniques: Instruments and index (Vol. 3, pp. 319-321). Thousand Oaks, CA: Sage.

Rousseau, S., \& Scharf, M. (2017). Why people helicopter parent? An actor-partner interdependence study of maternal and paternal prevention/promotion focus and interpersonal/self-regret. Journal of Social and Personal Relationships, 35, 919-935.

Sclove, S. L. (1987). Application of model-selection criteria to some problems in multivariate analysis. Psychometrika, 52, 333-343.

Schiffrin, H. H., \& Liss, M. (2017). The effects of helicopter parenting on academic motivation. Journal of Child and Family Studies, 26, 1472-1480. doi:10.1007/s10826-017-0658-z

Schiffrin, H. H., Liss, M., Miles-McLean, H., Geary, K. A., Erchull, M. J., \& Tashner, T. (2014). Helping or hovering? The effects of helicopter parenting on college students' well-being. Journal of Child and Family Studies, 23, 548-557. doi:10.1007/s10826-0139716-3

Schmitz, R. M. (2016). Constructing men as fathers: A content analysis of formulations of fatherhood in parenting magazines. The Journal of Men's Studies, 24, 3-23. doi:10.1177/1060826515624381

Segrin, C., Woszidlo, A., Givertz, M., Bauer, A., \& Taylor Murphy, M. (2012). The association between overparenting, parent-child communication, and entitlement and adaptive traits in adult children. Family Relations, 61, 237-252. doi:10.1111/j.1741-3729. 2011.00689.x

Smollar, J., \& Youniss, J. (1989). Transformations in adolescents' perceptions of parents. International Journal of Behavioral Development, 12, 71-84. doi:10.1177/016502548901200104

Stringer, K. J., \& Kerpelman, J. L. (2010). Career identity development in college students: Decision making, parental support, and work experience. Identity: An International Journal of Theory and Research, 10, 181-200. doi:10.1080/15283488.2010.496102

Vandenberg, R. J., \& Lance, C. E. (2000). A review and synthesis of the measurement invariance literature: Suggestions, practices, and recommendations for organizational research. Organizational Research Methods, 3, 4-70.

van Ingen, D. J., Freiheit, S. R., Steinfeldt, J. A., Moore, L. L., Wimer, D. J., Knutt, A. D., ... Roberts, A. (2015). Helicopter parenting: The effect of an overbearing caregiving style on peer attachment and self-efficacy. Journal of College Counseling, 18, 7-20. doi: 10.1002/j.2161-1882.2015.00065.

Videon, T. M. (2005). Parent-child relations and children's psychological well-being: Do dads matter? Journal of Family Issues, 26, 55-78. doi:10.1177/0192513x04270262

Wagner, C. R., \& Abaied, J. L. (2016). Skin conductance level reactivity moderates the association between parental psychological control and relational aggression in emerging adulthood. Journal of Youth and Adolescence, 45, 687-700. doi:10.1007/s10964016-0422-5

Weissman, M. M., Orvaschel, H., \& Padian, N. (1980). Children's symptom and social functioning self-report scales: Comparison 
of mothers' and children's reports. Journal of Nervous and Mental Disease, 168, 736-740. doi:10.1097/00005053-19801200000005

Wetherill, R. R., Neal, D. J., \& Fromme, K. (2010). Parents, peers, and sexual values influence sexual behavior during the transition to college. Archives of Sexual Behavior, 39, 682-694. doi:10.1007/ s10508-009-9476-8

White, H. R., McMorris, B. J., Catalano, R. F., Fleming, C. B., Haggerty, K. P., \& Abbott, R. D. (2006). Increases in alcohol and marijuana use during the transition out of high school into emerging adulthood: The effects of leaving home, going to college, and high school protective factors. Journal of Studies on Alcohol, 67, 810-822. doi:10.15288/jsa.2006.67.810

\section{Author Biographies}

Laura M. Padilla-Walker is a professor in the School of Family Life at Brigham Young University. She studies parenting and child development during adolescence and emerging adulthood.

Daye Son was a MA student at Brigham Young University at the time of this publication. She is currently a $\mathrm{PhD}$ student at Arizona State University studying parenting.

Larry J. Nelson is a professor in the School of Family Life at Brigham Young University. He studies flourishing and floundering during emerging adulthood. 